\title{
MEASUREMENT OF ANGULAR CORRELATION SOLID ANGLE CORRECTIONS FOR A COAXIAL Ge(Li) DETECTOR*
}

\author{
D. E. RAESIDE and M. L. WIEDENBECK
}

Physics Department, The University of Michigan, Ann Arbor, Michigan 48104, U.S.A.

\author{
Received 17 October 1969
}

Experimental finite solid-angle corrections have been determined for a coaxial $\mathrm{Ge}(\mathrm{Li})$ detector. A comparison between these experimental values and calculated values is shown.

In interpreting the results of gamma-gamma angular correlation measurements, one must take into account the finite so!id angles subtended by the detectors. The appropriate corrections for $\mathrm{NaI}(\mathrm{TI})$ crystals have been measured in many laboratories over the past 15 years.

* The work was supported in part by the U.S. Atomic Energy Conumission.
At present, because of the fact that the use of $\mathrm{Ge}(\mathrm{Li})$ detectors in gamma-gamma angular correlation measurements is relatively recent, there is little available information concerning the solid angle corrections for $\mathrm{Ge}(\mathrm{Li})$ detectors. We have determined the photopeak solid angle corrections ${ }^{1-3}$ )

$Q_{2}=\int N(\beta) \sin \beta P_{2}(\cos \beta) \mathrm{d} \beta / \int N(\beta) \sin \beta P_{0}(\cos \beta) \mathrm{d} \beta$
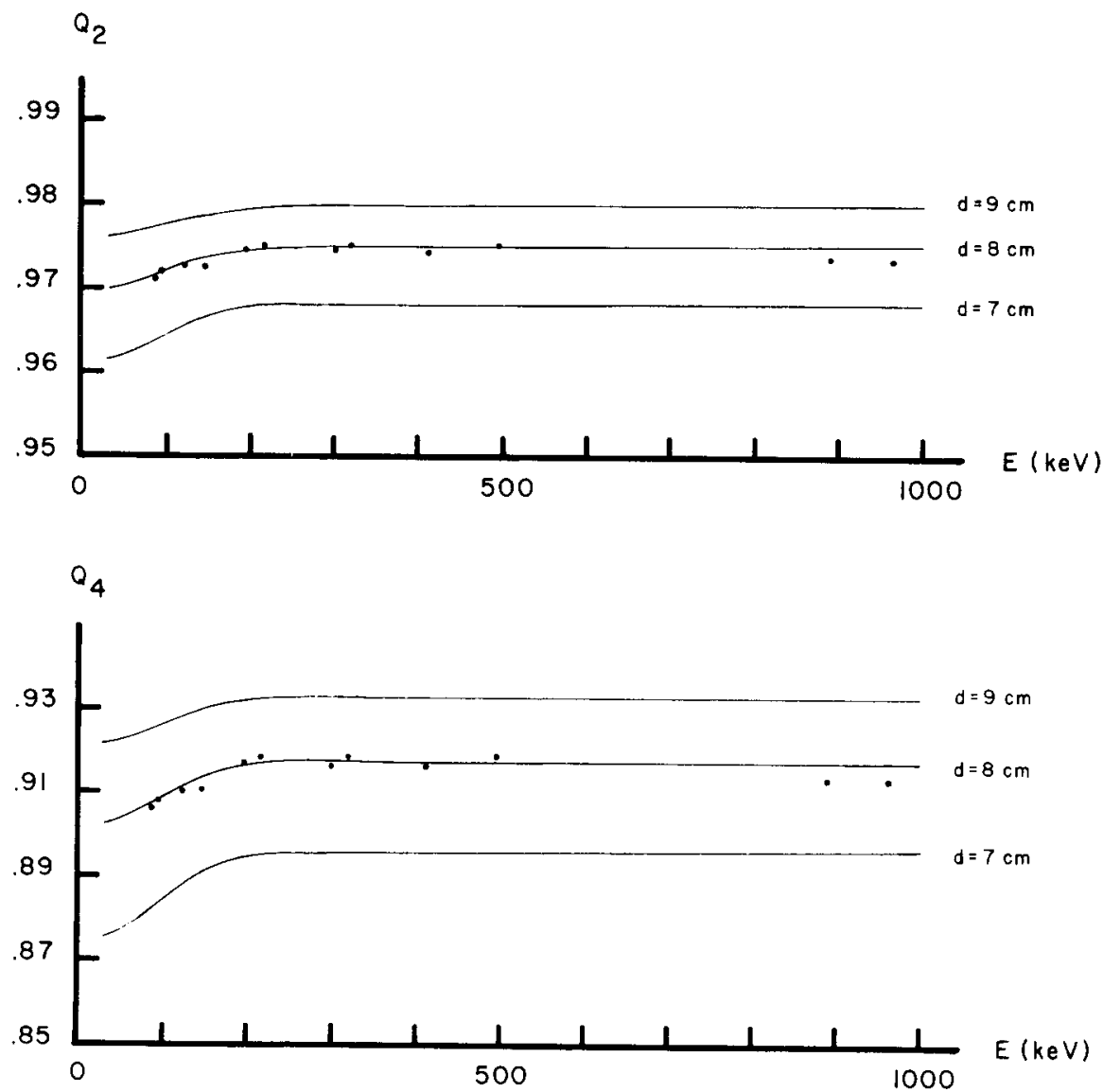

Fig. 1. A comparison between the experimental results of this investigation and the calculations of Camp and VanLehn ${ }^{4}$ ). A source-to-detector distance, $d$, of $8 \mathrm{~cm}$ was utilized in the experiment. The solid lines follow the calculated values of Camp and VanLehn, while experimental values are shown as heavy dots. 
and

$Q_{4}=$

$\int N(\beta) \sin \beta P_{4}(\cos \beta) \mathrm{d} \beta / \int N(\beta) \sin \beta P_{0}(\cos \beta) \mathrm{d} \beta$,

by means of a collimated beam experiment, for a coaxial $\mathrm{Ge}(\mathrm{Li})$ detector with the following characteristics: diameter $=32.200 \mathrm{~mm}$, n-region $=0.800 \mathrm{~mm}$, depletion depth $=8.200 \mathrm{~mm}$, length $=2.650 \mathrm{~cm}$, area $=5.770 \mathrm{~cm}^{2}$, volume $=15.292 \mathrm{~cm}^{3}$. Fig. 1 shows a comparison of our experimental results and the calculations of Camp and VanLehn ${ }^{4}$ ). The agreement is excellent.

\section{References}

1) M. J. L. Yates, Alpha-, beta-, and gamma-ray spectroscopy 2 (ed. K. Siegbahn; North-Holland Publ. Co., 1965) p. 1691.

2) B. Herskind and Y. Yoshizawa, Nucl. Instr. and Meth. 27 (1964) 104.

3) C. W. Reich and J. H. Douglas, Nucl. Instr. and Meth. 35 (1965) 67.

4) D. C. Camp and A. L. VanLehn, UCRL-71378 Report (1969); and private communications. 